\title{
Dose Volume Histogram
}

National Cancer Institute

\section{Source}

National Cancer Institute. Dose Volume Histogram. NCI Thesaurus. Code C112816.

A plot of a cumulative dose-volume frequency distribution that graphically summarizes the simulated radiation distribution within a volume of interest of a patient which would result from a proposed radiation treatment plan. 